\title{
The impact of pharmaceutical interventions on the rational use of proton pump inhibitors in a Chinese hospital
}

This article was published in the following Dove Press journal: Patient Preference and Adherence

\author{
Chuanwei Xin \\ Zhu Dong ${ }^{2}$ \\ Mengmeng Lin' \\ Gong-Hua $\mathrm{Li}^{\prime}$ \\ 'Department of Pharmacy, Zhejiang \\ Academy of Traditional Chinese \\ Medicine, Tongde Hospital of Zhejiang \\ Province, ${ }^{2}$ Department of Pharmacy, \\ the Fifth People's Hospital of Yuhang \\ District, Hangzhou, China
}

Background: The prescriptions of proton pump inhibitors (PPIs) have raised concern due to both huge increase in medical expenditure and the possible long-term adverse events caused by them; therefore, an approach to taper off the irrational use of PPIs by patients is clinically warranted. The aim of this study was to evaluate the impact of pharmaceutical interventions on the rational use of PPIs.

Patients and methods: A single-center, pre- to post-intervention study (pharmaceutical interventions group and control group) was performed in a Chinese hospital. Pharmaceutical interventions were performed in the post-intervention group, including educative group activities, real-time monitoring of clinical records and making recommendations to doctors on PPI prescriptions based on the criteria set at the beginning of the study. The number of patients with rational indication, the accuracy rate of administration route, the duration of therapy and the changes in total PPI costs, mean PPI costs, mean total drug costs and mean hospitalization costs were the main outcome measures.

Results: A total of 285 patients were included in the study. After 6 months of interventions, significant improvements in the number of patients with rational indication were found $(96.5 \%$ in the pharmaceutical interventions group vs $71.8 \%$ in the control group, $P<0.01$ ). The accuracy rate of administration route was increased $(99.3 \%$ vs $73.2 \%, P<0.05)$, while the duration of therapy was decreased $(7.9 \pm 0.5$ vs $14.3 \pm 0.8, P<0.01)$. Pharmaceutical interventions led to significant reductions in mean PPIs costs, mean total drug costs and mean hospitalization costs $(P<0.001)$.

Conclusion: This study provides important evidence on the beneficial effect of pharmaceutical interventions on enhancing the rational use of PPIs and substantial cost saving by increasing the number of patients with rational indication and reducing the risk for long-term adverse events. Keywords: proton pump inhibitors, pharmaceutical interventions, clinical pharmacist, indications, cost saving

\section{Introduction}

Proton pump inhibitors (PPIs) are widely applied in the treatment of peptic ulcers and acid-related dyspepsia, which are one of the most commonly prescribed types of drugs in the world. ${ }^{1}$ Over the past several years, there has been a significant increase in their use. A newly published study has shown that use of PPIs in noninstitutionalized adults in the USA doubled from $3.9 \%$ in 1999 to $7.8 \%$ in $2012 .^{2}$ According to a study from Batuwitage, ${ }^{3} 24 \%$ of patients admitted to hospital were prescribed a PPI, but only $54 \%$ had a rational indication for PPI treatment in these patients. Patients receiving irrational PPIs for periods of time may be more susceptible to adverse events (AEs)
Correspondence: Gong-Hua Li Department of Pharmacy, Zhejiang Academy of Traditional Chinese Medicine, Tongde Hospital of Zhejiang Province, 234 Gucui Road, Hangzhou 310012 , China

Tel +86 57I 89972240

Email xyaoshi9@163.com 
such as respiratory infections, Clostridium difficile infections, bone fractures, vitamin $B_{12}$ deficiency and hypomagnesemia. ${ }^{4}$ Furthermore, PPIs cost more than other acid inhibiting agents and the volume of prescribing has had a substantial impact on the health care cost in China. ${ }^{5}$

Since 2015, we have monitored the consumption of PPIs in our hospital and found a high level of prescriptions. There have been many aspects of inappropriate use of PPIs, such as an excess of drug prescriptions, the usage of doses higher than usual or long time of duration of therapy. The irrational use of PPI therapy may have a direct and serious impact on long-term patient care. The huge increase in prescriptions of PPIs should not be justified only by increased prevalence of acid-related diseases or extension of therapeutic indications. ${ }^{6}$

Previous studies have demonstrated successful interventions with many outcomes ranging from reduction of twicedaily dosing to once-daily dosing to full cessation of PPIs when not indicated. ${ }^{7,8}$ Other studies have demonstrated the cost-effectiveness and improvement in patient self-reported gastroesophageal reflux disease symptoms. ${ }^{9}$ However, fewer data have been produced regarding the impact of pharmaceutical interventions on the rational use of PPIs. Moreover, the knowledge relating to cost-outcome of pharmaceutical interventions is scarce in China. This study was designed to evaluate whether pharmaceutical interventions have a significant influence on the rational use of PPIs and medication cost savings.

\section{Patients and methods}

We conducted a single-center, pre- to post-intervention study to evaluate the impact of pharmaceutical interventions on the rational use of PPIs. Participants were enrolled in Tongde Hospital of Zhejiang Province, a 1800-bed South China teaching hospital in Hangzhou, serving over 95,000,000 patients in Zhejiang province. Patients who were admitted from June 1, 2016 to November 30, 2016, were enrolled in the control group, and patients admitted from February 1, 2017 to July 31, 2017, were enrolled in the pharmaceutical interventions group. Patients were eligible for inclusion if they were at least 18 years of age and had active orders for PPIs, with up-to-date results for their routine physical and laboratory tests in Tongde Hospital of Zhejiang Province. Patients with severe infections, liver failure and kidney disease, and patients declining to provide informed consent were excluded from our study. The Research Review committee of Tongde Hospital of Zhejiang Province approved the design of this study. Written informed consent was obtained from patients aged 18 or above to allow their information to be used for research.

The medical information of patients was identified through the Computerized Patient Record System, which listed all the information of inpatients who had received PPI therapy. Data on drug therapy and clinical condition were collected as follows: diagnoses, categories of PPIs, therapy indication, dosage, administration route, costs (costs of hospitalization, PPIs and other drugs), duration of therapy and comorbidities. The criteria for rational use of PPIs were established by the hospital administration with reference to the $2014^{10}$ and $2017^{11}$ evidence-based clinical practice guideline.

\section{Pharmaceutical interventions}

Patients enrolled in the control group received the usual care offered by the physicians, while patients in the pharmaceutical interventions group also received pharmaceutical intervention, besides the usual care. In this study, five clinical pharmacists were delegated by the Department of Hospital Administration to implement the interventions on the use of PPIs. During the course of pharmaceutical interventions, besides the daily round with the physician, educative group activities about the rational use of PPIs were carried out twice a month by clinical pharmacists. The activities discussed some themes such as indication of PPIs, dosage, administration route, new guidelines for PPIs and the risk of AEs. Presentations were made at the Department of Gastroenterology, the intensive care unit, the Department of Surgery and so on, with handouts left to be distributed to those not in attendance. During the pharmaceutical interventions, clinical pharmacists used an illustration to explain the rational use of PPIs, had a discussion with the doctor about the prescribed drugs and explained the pharmacologic characteristics of different PPIs and the possible drug interactions. After each intervention, the records about the acceptance rates of clinical pharmacist's recommendations were established.

\section{Outcome measures}

The primary aim of this study was to evaluate the impact of pharmaceutical interventions on the rational use of PPIs, the number of patients with rational indication, the accuracy rate of administration route, the change in total PPI costs, mean PPI costs, mean total drug costs, mean hospitalization costs and the duration of therapy, which were the main outcome measures. Secondary outcomes were prescriber acceptance rates and AEs between the two groups. All costs in Chinese Yuan currency were converted to US dollars (exchange rate, 6.3 Yuan $=$ US\$ 1). 


\section{Statistical analysis}

Data are expressed as mean \pm SD and analyzed using statistical analysis software (SPSS ${ }^{\odot}$ Version 18.0). Chi-square test and Student's $t$-test were performed to compare the groups. $P$-value $<0.05$ was statistically significant.

\section{Results}

Of the 295 patients assessed for eligibility, a total of 285 individuals completed this study; 142 were included in the control group and 143 in the pharmaceutical interventions group, as detailed in Figure 1. There were no statistically significant differences between the two groups in mean age, age bands, gender distribution and functional variables (Table 1). The mean age of the 143 patients in the pharmaceutical interventions group was $59.2 \pm 14.2$ years; about $58.7 \%$ were female, $36.4 \%$ smoked tobacco and $24.5 \%$ consumed alcohol.

Of the 143 patients in the pharmaceutical interventions group, there were 138 patients $(96.5 \%)$ with rational indication during 6 months of interventions, while in the control group, there were 102 patients $(71.8 \%)$ with rational indication. This rate showed a statistically significantly improvement $(P<0.05)$, representing an absolute risk reduction of $24.7 \%$. After 6 months follow-up, compared with the control group, the accuracy rate of administration route increased significantly $(99.3 \%$ vs $73.2 \%, P<0.05)$ and the duration of therapy decreased significantly $(7.9 \pm 0.5 \mathrm{vs}$ $14.3 \pm 0.8, P<0.01)$ in the pharmaceutical interventions group, as shown in Table 2. There were also more visible changes in different wards, with higher rates in gastroenterology, intensive care unit and surgery (Table 3 ). This could be attributed to the presentation and educative group activities, which were conducted by pharmacists in these three departments.

The difference in total PPI cost between the control and pharmaceutical interventions groups was indicated by net cost reduction in PPI use during the intervention period, which was $\$ 11,614.19$, as shown in Figure 2. The pharmaceutical interventions group had significantly lower mean PPI costs $(P<0.001)$, mean total drug costs $(P<0.001)$ and mean hospitalization costs $(P<0.001)$ than the control group. However, no significant difference was found in the length of hospital stay between the two groups (Table 4).

Secondary outcomes were prescriber acceptance rates and AEs between the two groups. A total of 322 recommendations were sent by clinical pharmacists during the study period; 288 of these recommendations were accepted, and thus, the prescriber acceptance rate of pharmacist recommendations

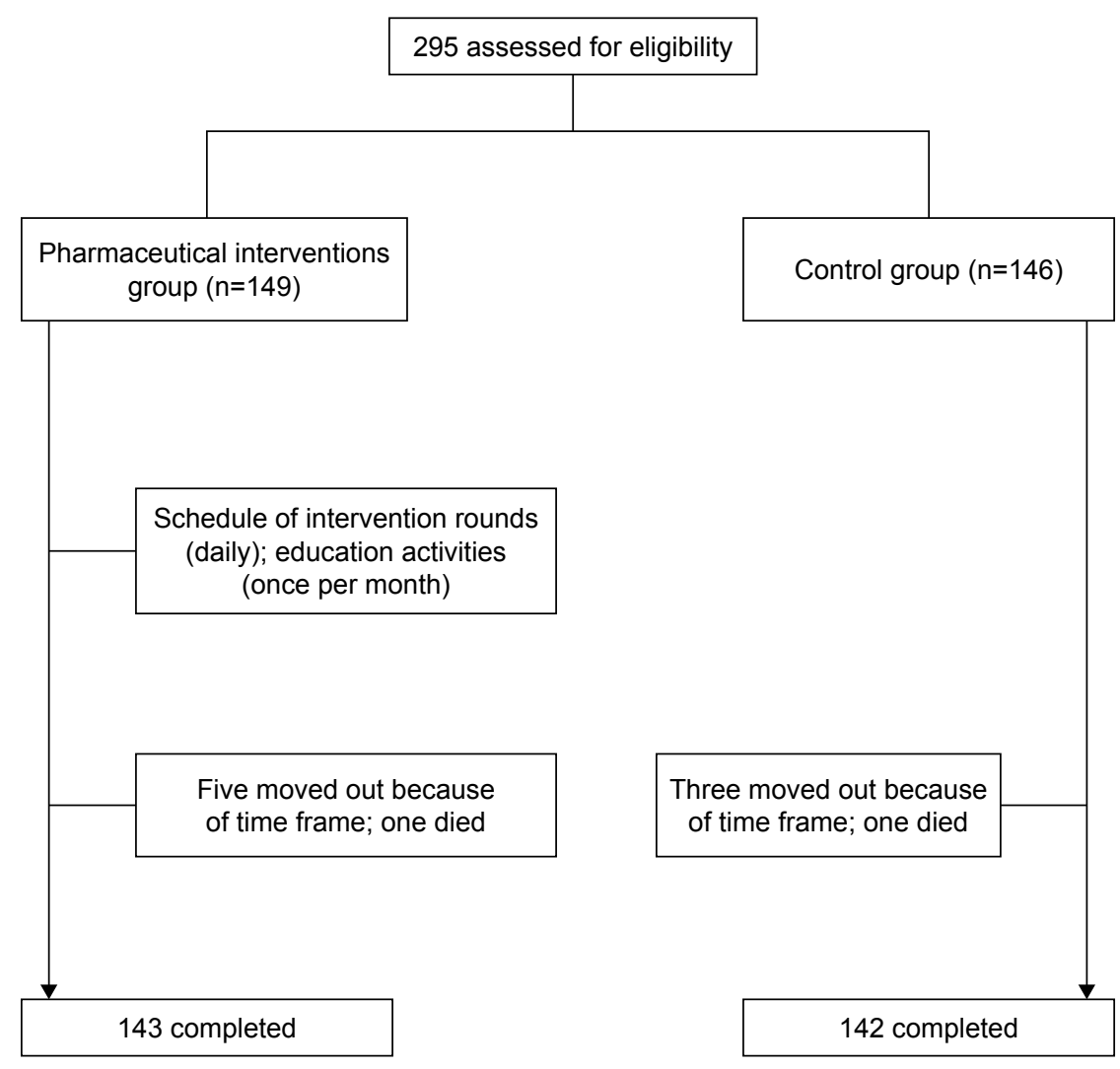

Figure I Flow chart of participants in the study. 
Table I Demographics and clinical characteristics of the two groups of patients

\begin{tabular}{|c|c|c|c|}
\hline Demographic characteristic & $\begin{array}{l}\text { Pharmaceutical } \\
\text { interventions group } \\
(\mathrm{N}=\mid \mathbf{4 3})\end{array}$ & $\begin{array}{l}\text { Control group } \\
(\mathrm{N}=\mid \mathbf{4 2})\end{array}$ & $P$-value \\
\hline Age, mean $\pm S D$, years & $59.2 \pm 14.2$ & $58.4 \pm \mid 3.5$ & 0.747 \\
\hline \multicolumn{4}{|l|}{ Sex, n (\%) } \\
\hline Female & $84(58.7)$ & $83(58.4)$ & 0.935 \\
\hline Mean body mass index, $\mathrm{kg} / \mathrm{m}^{2}($ mean $\pm \mathrm{SD})$ & $24.9 \pm 1.5$ & $24.7 \pm 1.4$ & 0.632 \\
\hline Tobacco use, $\mathrm{n}(\%)$ & $52(36.4)$ & $50(35.2)$ & 0.822 \\
\hline Alcohol use, n (\%) & $35(24.5)$ & $32(22.5)$ & 0.785 \\
\hline Hospitalization in previous 30 days, $n(\%)$ & $22(15.4)$ & $20(14.1)$ & 0.755 \\
\hline Antibiotics in previous 14 days, $\mathrm{n}(\%)$ & $19(13.3)$ & $17(12.0)$ & 0.751 \\
\hline \multicolumn{4}{|l|}{ Mean no of complications } \\
\hline Neurological, n (\%) & $14(9.8)$ & $15(10.5)$ & 0.788 \\
\hline Respiratory, n (\%) & $17(11.8)$ & $19(13.4)$ & 0.749 \\
\hline CVD, n (\%) & $25(17.5)$ & $27(19.0)$ & 0.793 \\
\hline
\end{tabular}

Abbreviation: CVD, cardiaovascular disease.

was $89.4 \%$. Compared with the control group, AEs in the pharmaceutical interventions group decreased significantly (7.69\% vs $35.2 \%, P<0.01)$, as shown in Table 5 .

\section{Discussion}

This study assessed the impact of pharmaceutical interventions on the rational use of PPIs. The results indicate that pharmaceutical interventions improved the number of patients with rational indication, increased the accuracy rate of administration route and decreased mean PPI costs, mean total drug costs, mean hospitalization costs and the duration of therapy over a 6-month period. By taking pharmaceutical rounds together with doctors and carrying out educative group activities in the process of pharmaceutical care, pharmaceutical interventions were able to provide a better support for the rational use of PPIs.

PPIs are one of the most prescribed drug categories worldwide. The most common irrational use of PPIs is overprescription (eg, without clear indication) rather than underprescription. According to a report by Zeng et al, ${ }^{12}$ there was an appreciable increase in PPI utilization by 10.4-fold during 2004 and 2013 in Chongqing district which was representative of China, and lack of monitoring of prescribing and the perverse incentives encouraging physicians to profit from drug procurement encouraged irrational prescribing. There are some studies documenting a high rate of irrational use of PPIs in patients, from $25 \%$ to $67 \%$, depending on different clinical settings. ${ }^{13-15}$ In our study, the main irrational indications of PPIs in the control group were prevention of stress ulcer in low-risk patients and unwarranted gastro-protection, including different patients undergoing routine surgical procedures. Thus, we carried out a pre- to post-intervention study to evaluate the impact of pharmaceutical interventions on the rational use of PPIs. Our results showed that the number of patients with rational indication enrolled in the pharmaceutical interventions group increased significantly after 6 -month interventions $(96.5 \% \mathrm{vs}$ $70.8 \%, P<0.01)$. This may be attributed to clinical pharmacists adopting an active pharmaceutical intervention strategy, which involved daily rounding and educative activities.

Considering the large population base in China, irrational PPI use may lead to escalation in prescribing care cost in China. Therefore, it is necessary to demonstrate costeffective interventions and improve cost saving in PPI use

Table 2 The primary outcome measures of the two groups

\begin{tabular}{|c|c|c|c|}
\hline Outcome measures & $\begin{array}{l}\text { Pharmaceutical } \\
\text { interventions group } \\
(\mathrm{N}=143)\end{array}$ & $\begin{array}{l}\text { Control group } \\
(\mathrm{N}=\mid \mathbf{4 2})\end{array}$ & $P$-value \\
\hline Patients with rational indication, $\mathrm{n}(\%)$ & $138(96.5)$ & $102(71.8)$ & 0.0049 \\
\hline $\begin{array}{l}\text { Patients with an accuracy of } \\
\text { administration route, } \mathrm{n}(\%)\end{array}$ & $142(99.3)$ & $104(73.2)$ & 0.0032 \\
\hline Duration of therapy (days), mean \pm SD & $7.9 \pm 0.5$ & $14.3 \pm 0.8$ & 0.0028 \\
\hline Recommendations & 322 & 0 & \\
\hline
\end{tabular}


Table 3 Rational use of PPIs in different wards by the two groups

\begin{tabular}{|c|c|c|c|c|c|}
\hline \multirow[t]{2}{*}{ Ward } & \multicolumn{2}{|c|}{$\begin{array}{l}\text { Pharmaceutical interventions } \\
\text { group }(\mathbf{N}=143)\end{array}$} & \multicolumn{2}{|c|}{ Control group $(\mathrm{N}=\mid 42)$} & \multirow[t]{2}{*}{$P$-value } \\
\hline & $\begin{array}{l}\text { Number } \\
\text { of patients }\end{array}$ & $\begin{array}{l}\text { Rational use } \\
\text { of PPIs, } n \text { (\%) }\end{array}$ & $\begin{array}{l}\text { Number } \\
\text { of patients }\end{array}$ & $\begin{array}{l}\text { Rational use } \\
\text { of PPIs, n (\%) }\end{array}$ & \\
\hline Endocrinology & 9 & $6(66.7)$ & 11 & $5(45.5)$ & 0.042 \\
\hline Orthopedics & 17 & $14(82.4)$ & 15 & $9(60)$ & 0.038 \\
\hline ICU & 22 & $20(90.9)$ & 24 & I4 (58.3) & 0.012 \\
\hline Gastroenterology & 35 & $33(94.3)$ & 37 & $22(59.5)$ & 0.009 \\
\hline Surgery & 28 & $27(96.4)$ & 24 & $9(37.5)$ & 0.005 \\
\hline Psychiatry & 4 & $3(75)$ & 5 & $3(60)$ & 0.037 \\
\hline Neurology & 20 & $17(85)$ & 18 & I4 (77.8) & 0.078 \\
\hline Cardiology & 8 & 7 (87.5) & 8 & $5(62.5)$ & 0.043 \\
\hline
\end{tabular}

Abbreviations: ICU, intensive care unit; PPIs, proton pump inhibitors.

in Chinese hospitals. Our results showed that substantial cost of PPIs and the economic burden of the patients in this study were significantly decreased by pharmaceutical interventions. Therefore, for promoting rational use of PPIs and reducing the economic burden of patients, it is urgent for the hospital administration to develop effective drug administration policy.

To our knowledge, this study is the first to evaluate the prescriber acceptance rates of pharmacist recommendations on the rational use of PPIs in Zhejiang province of China. It was found that $89.4 \%$ recommendations were accepted in the pharmaceutical interventions group. Accordingly, AEs in the pharmaceutical interventions group were decreased significantly. For every patient, the risk-benefit profile of PPIs should be carefully considered. ${ }^{16}$ The prescriptions of PPIs as well as all other drugs should be carefully evaluated by the doctors. Furthermore, every indication of drugs should be patient-based rather than only guideline-based. ${ }^{17}$ This study highlights that pharmaceutical intervention may be most effective with rational use of PPIs.

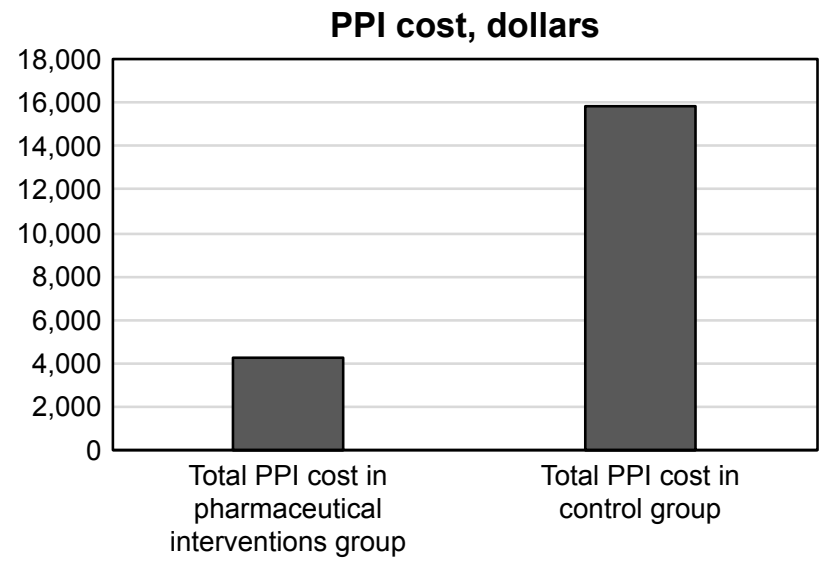

Figure 2 Cost of PPI before and after pharmaceutical interventions. Abbreviation: PPI, proton pump inhibitor.

\section{Limitations}

While this study has a lot of methodological strengths, there are several limitations. This intervention study was based on a pre-post design, without involving a parallel control group, and the robustness of this pre-post study is debatable. ${ }^{18}$ Data of this study were obtained from a single center, and were of a short-term period and a relatively lower number of samples, so the patients may not fully represent the overall general population. Furthermore, evaluation of the rational use of PPIs was mainly based on the drug instructions and current guidelines; therefore, the estimates presented here are possibly conservative. Future study with a larger sample size and a more rigorous design needs to be performed. In spite of the limitations, this study has identified significant improvement on the rational use of PPIs, and it can provide comparative and feedback information in optimizing the use of PPIs.

\section{Conclusion}

This study with a pre- to post-intervention design provides important evidence on the beneficial effect of pharmaceutical interventions to enhance the rational use of PPIs. The pharmaceutical interventions may promote rational use of PPIs by increasing the number of patients with rational indication and reducing the costs of PPIs, costs of total drugs,

Table 4 The medical cost: pre-intervention vs post-intervention

\begin{tabular}{|c|c|c|c|}
\hline Cost (USD) & $\begin{array}{l}\text { Pharmaceutical } \\
\text { interventions group } \\
(\mathrm{N}=\mid \mathbf{4 3})\end{array}$ & $\begin{array}{l}\text { Control group } \\
(\mathrm{N}=142)\end{array}$ & $P$-value \\
\hline $\begin{array}{l}\text { Mean total } \\
\text { hospitalization cost }\end{array}$ & I,328.4 & I,795.2 & $<0.001$ \\
\hline Mean total drug cost & 598.5 & 824.9 & $<0.001$ \\
\hline Mean PPI cost & 91.9 & 332.8 & $<0.001$ \\
\hline $\begin{array}{l}\text { Mean hospitalization } \\
\text { days }\end{array}$ & 15.2 & 15.8 & 0.595 \\
\hline
\end{tabular}

Abbreviation: PPI, proton pump inhibitor. 
Table 5 Rates of adverse events in the two groups during the study period

\begin{tabular}{|c|c|c|c|}
\hline Adverse events & $\begin{array}{l}\text { Pharmaceutical } \\
\text { interventions group } \\
(\mathrm{N}=\mid 43), \mathrm{n}(\%)\end{array}$ & $\begin{array}{l}\text { Control group } \\
(\mathrm{N}=142) \text {, n (\%) }\end{array}$ & $P$-value \\
\hline Clostridium difficile associated diarrhea & $3(2.09)$ & $14(9.86)$ & 0.0035 \\
\hline Patients treated for respiratory infections & $2(1.40)$ & $15(10.5)$ & 0.0028 \\
\hline Hypomagnesemia & $4(2.79)$ & $10(7.04)$ & 0.025 \\
\hline Skeletal muscle adverse reactions & I $(0.70)$ & $6(4.22)$ & 0.0024 \\
\hline Psychiatric symptoms & I $(0.70)$ & $5(3.52)$ & 0.047 \\
\hline Total & II (7.69) & $50(35.2)$ & 0.0015 \\
\hline
\end{tabular}

costs of hospitalization and the risk for long-term AEs. To confirm the generalizability of our findings, a multicenter, prospective, randomized controlled study is warranted in large samples of patients.

\section{Acknowledgments}

We would like to acknowledge Dr Weijia Li (research question development, study selection) and Mrs Ting Xia (data analysis, interpretation of results) for their involvement. This study was supported by National Natural Science Foundation of China (81774270) and the new medical talent training plan of Zhejiang Province in 2017, Tongde Hospital of Zhejiang Province (2D01703), the fund of science and technology of Yuhang district (medical plan 2016017).

\section{Disclosure}

The authors report no conflicts of interest in this work.

\section{References}

1. Larsen MD, Schou M, Kristiansen AS, Hallas J. The influence of hospital drug formulary policies on the prescribing patterns of proton pump inhibitors in primary care. Eur J Clin Pharmacol. 2014;70(7):859-865.

2. Freedberg DE, Kim LS, Yang YX. The risks and benefits of long-term use of proton pump inhibitors: expert review and best practice advice from the American Gastroenterological Association. Gastroenterology. 2017;152(4):706-715.

3. MacLaren R, Kassel LE, Kiser TH, Fish DN. Proton pump inhibitors and histamine-2 receptor antagonists in the intensive care setting: focus on therapeutic and adverse events. Expert Opin Drug Saf. 2015;14(2):269-280.

4. Buendgens L, Bruensing J, Matthes M, et al. Administration of proton pump inhibitors in critically ill medical patients is associated with increased risk of developing Clostridium difficile-associated diarrhea. J Crit Care. 2014;29(4):696.e11-e15.

5. Xu HB, Wang HD, $\mathrm{Li} \mathrm{CH}$, et al. Proton pump inhibitor use and risk of spontaneous bacterial peritonitis in cirrhotic patients: a systematic review and meta-analysis. Genet Mol Res. 2015;14(3):7490-7501.
6. Lodato F, Poluzzi E, Raschi E, et al. Appropriateness of proton pump inhibitor (PPI) prescription in patients admitted to hospital: attitudes of general practitioners and hospital physicians in Italy. Eur J Intern Med. 2016;30:31-36.

7. Inadomi JM, McIntyre L, Bernard L, Fendrick AM. Step-down from multiple- to single-dose proton pump inhibitors (PPIs): a prospective study of patients with heartburn or acid regurgitation completely relieved with PPIs. Am J Gastroenterol. 2003;98(9):1940-1944.

8. Ramser KL, Sprabery LR, Hamann GL, George CM, Will A. Results of an intervention in an academic internal medicine clinic to continue, step-down, or discontinue proton pump inhibitor therapy related to a tennessee medicaid formulary change. J Manag Care Pharm. 2009;15(4):344-350.

9. Bundeff AW, Zaiken K. Impact of clinical pharmacists' recommendations on a proton pump inhibitor taper protocol in an ambulatory care practice. J Manag Care Pharm. 2013;19(4):325-333.

10. Chinese National Expert Committee on Rational Drug Use. Guidelines for Chinese Doctors and Pharmacists. 2nd ed. Chongqing: Chongqing press; 2014:741-760.

11. Farrell B, Pottie K, Thompson W, et al. Deprescribing proton pump inhibitors: evidence-based clinical practice guideline. Can Fam Physician. 2017;63(5):354-364.

12. Zeng W, Finlayson AE, Shankar S, de Bruyn W, Godman B. Prescribing efficiency of proton pump inhibitors in China: influence and future directions. BMC Health Serv Res. 2015;15:11.

13. Sachar H, Vaidya K, Laine L. Intermittent vs continuous proton pump inhibitor therapy for high-risk bleeding ulcers: a systematic review and meta-analysis. JAMA Intern Med. 2014;174(11):1755-1762.

14. Lo EA, Wilby KJ, Ensom MH. Use of proton pump inhibitors in the management of gastroesophageal varices: a systematic review. Ann Pharmacother. 2015;49(2):207-219.

15. Haastrup P, Paulsen MS, Begtrup LM, Hansen JM, Jarbøl DE. Strategies for discontinuation of proton pump inhibitors: a systematic review. Fam Pract. 2014;31(6):625-630.

16. MacLaren R, Reynolds PM, Allen RR. Histamine-2 receptor antagonists vs proton pump inhibitors on gastrointestinal tract hemorrhage and infectious complications in the intensive care unit. JAMA Intern Med. 2014;174(4):564-574.

17. Pappas M, Jolly S, Vijan S. Defining appropriate use of proton-pump inhibitors among medical inpatients. J Gen Intern Med. 2016;31(4): 364-371.

18. Barletta JF, Sclar DA. Use of proton pump inhibitors for the provision of stress ulcer prophylaxis: clinical and economic consequences. Pharmacoeconomics. 2014;32(1):5-13.
Patient Preference and Adherence

\section{Publish your work in this journal}

Patient Preference and Adherence is an international, peer-reviewed, open access journal that focuses on the growing importance of patient preference and adherence throughout the therapeutic continuum. Patient satisfaction, acceptability, quality of life, compliance, persistence and their role in developing new therapeutic modalities and compounds to optimize

\section{Dovepress}

clinical outcomes for existing disease states are major areas of interest for the journal. This journal has been accepted for indexing on PubMed Central. The manuscript management system is completely online and includes a very quick and fair peer-review system, which is all easy to use. Visit http://www. dovepress.com/testimonials.php to read real quotes from published authors. 